munity school, it will take the pattern of its content from the discriminants and determinants of its own community. If the junior high-school administrator will bear in mind that the junior high school is an educational setup designed to help the young adolescent establish himself satisfactorily in his community, he can measure against this criterion the value of all activities including the study of English.

In short, we expect of young adolescent pupils that they must begin to discover themselves in relation to their social environment. Through contact and associations they must develop social insights. They must organize their social attitudes and mature their adjustment to laws, folkways, customs, tradition, and other mechanisms of our culture. They must come to grips with such realities as problems of democracy, of inter-racial harmony, of family life, of higher education, and of economic and social evil. They must achieve civic understanding and the ability to live together within a democratic American community. These fundamental cores of interest, experience, and activity are the centers around which the expression of English study in a junior high school will revolve. Through literature, creative writing, communication, appreciative understanding, and the other activities of English, the junior highschool pupil learns life as he learns literature.

In closing, it may be said quite frankly that no one has yet with any degree of authority defined the exact nature of English in the junior high schools. Perhaps this is so because such a definition would violate the very nature of the junior high school. The junior high school must not become a definitive type of organization, confirmed in organized precedure. It must remain flexible and tentative - a type of educational service rather than an institution. It must remain that area of the school set-up in which our young adolescents, having learnt in some degree the elementary skills of human contact, as these are taught in the grammar schools, are now afforded the chance to start their process of social growth. English teaching in the junior high school will adjust itself to the needs of this process.

\title{
II. Knowedge and Skills in English That May Be Expected of the High-School Student Entering College
}

\author{
$\begin{array}{lll}\text { C L A RE N CE D. THORPE } & \text { D O }\end{array}$ \\ Department of English, University of Michigan, Ann Arbor
}

THE PROBLEM OF ARTICULATION

$7 \mathrm{HE}$ question of adequate preparation in English for the college freshman has in the past few years been receiving more and more serious attention. The issue, of course, is really one of articulation, a concept that merits more consideration than modern education has been inclined to give it. It is, therefore, a hopeful sign when we see groups of teachers and administrators in 
different parts of the country engaged in studies and projects, some of them state-wide in scope, designed to find ways to effect a smoother juncture between high school and college in the large area of knowledge and skills covered by the comprehensive term English. ${ }^{1}$

English has been and will remain a basic subject in the school curriculum. This would be so if all English classes as such were abolished tomorrow. For English has primarily to do with the use of our language for getting and utilizing ideas; and the getting and utilizing of ideas is the principal business of education. How well are we succeeding in training our students in this allimportant discipline? Ask a group of college men this question, and they will promptly and emphatically tell you that the high schools are not doing a very good job of it. The high schools will in turn declare that the elementary division is failing, just as, if you go in the other direction, the graduate schools of our universities would slyly admit that the colleges are not making much of a go at turning out students who are properly skilled in using language. All of which may be another way of saying that we have not as yet learned to teach English in such a way as to get very good results.

The situation calls for tolerance and wisdom. It must be recognized at the start that the problem of acquiring satisfactory knowledge and skills in English is difficult and complex, and that there is no one magic formula to resolve it. One thing is certain: the remedy does not lie in grumbling and mutual recrimination, but rather in a clear-eyed facing-up to the issues and a

1The following publications, all bearing directly or indirectly on the problem of articulation, will indicate something of the extent of the activity of which the author is speaking:

"Rhetoric Proficiency Tests at the University of Illinois," Illinois English Bulletin (March, 1944), Urbana, Illinois; also, The Problem of English Composition in American Colleges and Universities, a Bulletin of the University of Illinois, Urbana.

Suggestions Regarding Levels of Accomplishment in Written Composition, a Bulletin prepared by the University of Wisconsin and the Wisconsin Department of Public Instruction, Madison; also Robert C. Pooley, "Achieving Continuity in High School and College English," College English, 6 (Dec., 1944), 149-156.

Studies in Articulation, University of Buffalo Studies, Series II, Bulletins 3, 5, 6, 7, 8, Vol. XIII (1936); also $A$ Charter for the Superior Student, ibid., No. 3, Vol. II (1936).

Report of the Language Committee (Apri1, 1940) and Report of the Literature Committee (April, 1942), School and College Conference on English. Copies of these reports may be obtained from Doublas A. Shepardson, Box 308, Wallingford, Connecticut.

$A$ Report of Principal Difficulties and Suggested Remedies, prepared by St. Louis and Washington University Teachers of English, St. Louis, Washington University, 1942.

Warner G. Rice, "Articulation of Secondary School and College English," College EngIish, 2 (Nov., 1940), 136-145.

John C. Hodges, "The State-Wide English Program in Tennessee." College English. 6 (May, 1945), 448-453.

Preparation for College English: An Interpretation of College Entrance Standards in English, by the Michigan Committee on the Articulation of High School and College English, ed. by Clarence D. Thorpe (Ann Arbor, University of Michigan Press, 1942, 1945); also Clarence D. Thorpe, "Toward a Better Program in English: the Factor of Articulation in Elementary School, High School, and College English," Illinois English Bulletin, 32 (February, 1945), Urbana, Illinois; and Clarence D. Thorpe, "Factors of Growth in the Language Arts in College, with Special Reference to Articulation," College English, 6 (March, 1945), 331-338.

Other studies are under way. Minnesota and Indiana have been working on the subject for some time, and Kansas has recently begun a state-wide project looking toward improved articulation. A beginning has also been made in California. 
unified effort to meet them; and this indicates, among other things, a need for better articulation between and within the various units.

Articulation between units is obviously a double-edged affair. So far as the colleges and secondary schools are concerned, it is not a matter of the colleges' setting up arbitrary and absolute requirements, nor of the high schools' acting as sole arbiters on the way they prepare students for college; it is rather one upon which the two parties concerned should come to terms. It involves both what the colleges may reasonably hope for in the preparation of entering freshmen in language-composition and in reading-literature and what the secondary schools are able and willing to accomplish in the way of such preparation. The logic of the situation and the principle of fairness to students would suggest that the colleges and the secondary schools get together on this important matter to the end of the clearest possible understanding of what the colleges regard as essential and what the schools are prepared to furnish. Only in such co-operation may there be satisfactory articulation. There is really no other way to avoid serious and often, for the students concerned, disastrous gaps between high-school attainment and college requirements.

But we must go further than this. If the high-school graduate is to be prepared adequately in English for the rigors of college work he should have enjoyed the advantages of a well-planned, well-articulated program in the language arts beginning in the lower grades and continuing through junior high school and senior high school. This is something that seldom happens at present. It is more likely that he has come up through an arrangement whereby each unit in the school system goes on in its own sweet way in English, with small regard to what has gone before or to what is coming after. If many years' study of the pre-college English situation has left with the writer one single impression that stands out above all others (even above the fact of the amazingly large proportion of inadequately prepared teachers in the English classrooms), it is that of the heedless, one might almost say stubborn, disregard of the logic of a cumulative, vertically articulated program in language composition and reading-literature for the twelve years leading to the highschool diploma. Along with this goes an apparent reluctance to set up anything like specific goals of attainment at any given level, say for the end of the sixth grade, the end of the junior high school, and the end of the senior high school. One big stumbling block here is the fact of individual differences and the necessity of making provision for them. The setting of specific attainments, moreover, smacks to some of regimentation and traditionalism. Yet, if we have no definite goals, at least for the bright-normal pupil, are we not working pretty much in the dark, without direction or clear purpose?

All this in the end is to a large extent an administrative responsibility. No single teacher or group of teachers in one unit, no single principal can do much about it. Without co-ordination from the top there is still likely to remain, after the best effort of the English teachers, the spectacle of a carefully 
organized senior high-school program constructed without reference to and in complete ignorance of what is done in the junior high school. The co-operative effort of teachers and principals under the leadership of their superintendent is plainly the only way to achieve a unified, well-articulated program. In smaller systems the problem is simpler; though a special obstacle to continuity here is the relatively rapid turn-over of teachers.

The writer has said, and now says it again, that if carefully planned cumulative and logically articulated prgorams in English were generally adopted in our schools and if the right content in the hands of the right teachers were put into these programs, English teaching in America would be revolutionized within a decade. And one radical change would be that the colleges would no longer need to do what many of them frankly admit they are doing; that is, covering ground in their elementary English courses that should, for the most part, have been covered in the high school. It is to be hoped, too, that the colleges themselves would then go on to provide for their students intelligently articulated programs in the language arts.

In the meantime, what, under present conditions, may reasonably be expected of the student entering college in the way of knowledge and skills in English? What may the colleges look for and what are the schools prepared to furnish? Before we come more specifically to this question the writer wants to say a word about the terms knowledge and skills as he shall use them in the rest of this article and to discuss briefly the place of English in the educational process.

\section{KNOWLEDGE AND SKILLS}

When we speak of skills in English we have in mind the student's ability to do things: to get meaning in silent reading, to read well orally and to speak well, and to use words in effective combinations for the expression of ideas in written form with a decent regard for mechanics and social acceptability. By knowledge in English we ordinarily have reference to command of facts about language and literature. We talk about a knowledge of grammatical terms and forms and rules, about knowing the meaning of words, the ways of English speech, the basic rhetorical principles, and the facts concerning writers and their works.

The writer wishes, however, to use the word knowledge in a somewhat broader application, extending its meaning to include something of what Newman had in mind in his distinction between learning and knowledge. Newman's point is that learning (the acquisition of surface facts) becomes knowledge only when it reaches the stage of meaningful realization; that is, when facts are seen in their implications and relationships, or when they are experienced. In this sense mere memory of isolated facts is not knowledge, neither are rules detached from functional application nor things read from books without reflective extension to life and its varied problems. For in order to become a part of knowledge words and facts must be carried from 
the plane of symbol to one of reality. "Nothing," declared the young Keats, with a wisdom beyond his years, "is real until it is experienced."

To have a real knowledge of anything in this sense means, first of all to have firm possession of it mentally. It means a kind of teaching that goes beyond mere telling. A keen-minded youngster was asked by his father, as they were taking a Sunday afternoon walk, if he could "box the compass" for him. The boy promptly gave him the sixteen cardinal points, and stopped. "What about the other sixteen?" inquired the father. "Didn't I teach you all of them?" "You told me about them," replied the boy, "but you didn't teach them to me." The father turned in and taught the missing points, and by the time they reached home the lad had them well in hand. Here is a pedagogical lesson for teachers to take to heart. We teachers are often better at telling than at teaching. Telling is much the easier process, and the temptation to stop there is great, especially in consideration of the fact that we are characteristically an outfit of chronic talkers.

There is, however, a step beyond the kind of knowledge this boy had of the compass, even after the more thorough teaching, and that is the understanding that would come through personal acquaintance with the instrument, eventuating in fuller realization of its values and in ability to make use of it.

What this statement amounts to in terms of the present discussion is that one of the most essential things a student can get from his high-school English is an understanding of what English is all about: why it is important, what it is good for, what is the real place of language and literature in education and in our daily lives. Exposure to the principles of reading and grammar and rhetoric and to the rules of punctuation is, therefore, not enough; nor will drill and practice in applying them suffice. Pupils must, in addition, be helped to see the rationale of acceptable grammatical usage, the logic of right punctuation, the reasons for reading well and writing and speaking well. They must, that is, have some understanding of the values of English for themselves as individuals and as social beings. Such understanding is motivation in the best sense - the only kind of motivation that is in the end productive of right attitudes and of willing, self-sustaining effort.

THE UTILIZATION OF KNOWLEDGE

"Education," says Professor Whitehead, "is the acquisition of the art of the utilization of knowledge." In another place he speaks of the "unimportance - indeed the evil — of barren knowledge." For, he asserts, "The importance of knowledge lies in its use, in our active mastery of it." ${ }^{3}$ Whitehead is here saying in another way what William James had in mind when he insisted that in education there should be no impression without expression. To fill the mind with impressions - ideas, knowledge - without using these im-

\footnotetext{
${ }^{2}$ A. H. Whitehead, The Aims of Education and Other Essays (New York, The Macmillan Company, 1942), p. 6.

IIbid., p. 49.
} 
pressions in a free out-flow of expression is to build, as it were, a sort of mental graveyard in which there lie only the dead ashes of lifeless ideas. "Inert ideas," Whitehead calls them:

In training a child to activity of thought, above all things we must beware of what I will call 'inert ideas' - that is to say, ideas that are merely received into the mind without being utilized or tested, or thrown into fresh combinations. 4

These words have great significance for their bearing on the educational process in general; but they have a particular application to the English problem.

Ideas may be utilized by mulling over in the mind what has been read or heard or experienced, by sorting out the important from the unimportant, by comparing and judging, by adjusting thought to thought, and by thinking things through to logical conclusions. All this is a part of the reading process. Reading is useful only when something is done with what is read; otherwise much reading may become a sort of mental dissipation, even a vice. The student who began her book report with the sentence, "When I finished reading this book I sat for a long time thinking over what was in it and what it all came to," had learned a fine lesson: she had found an effective antidote for the curse of "inert ideas."

After the thinking comes expression, an indispensable part of the process of keeping ideas alive. Expression is necessary because it is the best way there is to channel and organize thought, to test it out, to capture it and make it our own. Indeed, without expression knowledge can scarcely be considered knowledge at all. Expression is a matter of putting ideas into words, but until words can be found who knows what the idea is? One cannot think except in words, in words, moreover, that have been put together to form logical units of expression - sentences, paragraphs, longer composition. Certainly one cannot communicate connected thought except through intelligible combinations of words - barring, of course, the limited utility of symbols in technical subjects.

Boys or girls who come to college inadequately trained in the art of expression are, therefore, likely to be poor risks, are at best at a great disadvantage. They are pretty certain to be weak in thought and inept and inarticulate in conveying what little they may have in their heads. Even those students who have had a fair preparation will need further training; for the power to utilize knowledge through expression is a relative one, in which continuous exercise is essential to continued growth of mind. That is why the course in freshman composition is almost a universal requirement in American colleges. It also explains the general incompetence in expression of college students whose high-school programs have been built on the fallacy that composition work can all be done in a semester or a year and then forgotten.

Ibid. 
WHAT THE COLLEGES WANT

Let us now return to the question of what degree of attainment in knowledge and skills in English may be expected of the entering college freshman. There is probably less difference between the colleges and secondary schools on this matter than is sometimes assumed. The colleges have long since ceased to be perfectionists in their expectations, and they have tended more and more to think in terms of evidence of ability than in terms of formal requirements. For example, entrance examinations in English have in the past twenty-five years shown a trend away from merely factual questions toward exercises that test the power of the student to do something with what he has learned both in and out of the classroom; there is more emphasis on proof of ability to reflect critically on what has been read or heard and to make applications to personal and social problems, less on memory and coverage. Similarly, the statement of entrance requirements by the North Central Association stresses attainment and ability to do rather than coverage. And the same tendency is to be observed in colleges that have expressed their standards in other ways, notably in those working with the high schools in articulation programs.

What the colleges most want in an entering freshman, is, the writer judges, an intelligent human being who has the capacity and the proper foundation for growth. They want evidence of quality of mind. They are looking for students who know an idea when they see one and know what to do with it. They are much interested in positive attitudes and right habits of study. So far as English is concerned they want the kind and amount of training that will enable the student to do college work. They regard English as a vital subject because the skills with which it is concerned are indispensable to success in college courses. They, therefore, place a fair capability in the fundamental skills about specialized knowledge about the lesser things. They want students who can read well enough to get new ideas from books. They value creative minds, but they are not much interested in candidates who have specialized in flowery or fanciful writing. Other things being equal they prefer a student who can explain in a clear, graphic way what he sees under a microscope to one who can fling his language about in a fantastical story. They desire literacy, of course, and general social acceptability in the use of language. And they also wish for the rather special ability to read imaginative literature with enjoyment and understanding and with some critical evaluation.

\section{LANGUAGE AND COMPOSITION}

If the ability to utilize knowledge through clear and orderly expression is indispensable to the college student, to what degree should this ability be developed in the secondary school? Any answer to this question must, at best, be relative, to be arrived at through approximation and illustration, not by arbitrary rule of thumb, for no satisfactory test for proficiency in conveying thought has as yet been devised. Vocabulary and usage tests may be used with 
some satisfaction, it is true; but adequate tests in composition are yet to be invented. We can say with confidence, however, that what is desired of the college freshman is that he shall have attained a reasonable command of the knowledge and skills essential to competent and socially acceptable communication, and that he shall have had enough practice in writing and speaking to have made their application to some degree habitual.

Competent expression is expression that does its job. Its end is the successful communication of ideas in clearly thought-out, well-organized units of sentence, paragraph, and theme. It is controlled, channeled expression, keeping within the limits of the immediate purpose of the writer or speaker and making every sentence count toward achieving this purpose; it knows when to stop, but it also goes on until the intended meaning is adequately, that is intelligibly, conveyed. Acceptable expression is that in which the decencies are observed: it is, in other words, expression that shows such a command of received usage in language as not to offend the taste of cultivated people. It means "a reasonable proficiency in grammatical forms and in general mechanics: good sentence structure, good spelling, adequate punctuation, freedom from offensive grammatical and rhetorical errors." ${ }^{\text {It }}$ It also means, however, freedom from pedantic, stilted, over-nice language: that English is best which is idiomatic - one that is never too far divorced from the strong, natural, even homely, voice of speech; it keeps within the boundaries of acceptable form, but it is neither artificial nor over-formal.

\section{Organization}

The matter of organization of thought in oral and written composition which students apply cannot be stressed too much. Unfortunately, skill in organizing ideas does not come naturally to any of us, young or old, but must be worked for, with purpose and intelligence. Most of our discourse as we grow up, as in conversation, is sporadic and associational rather than directed and unified. It is only when we begin to think and to have regard for orderly processes of thought that we find a need for organizing our ideas into welldefined units of sentence, paragraph, and theme, with such development and such sequence that the reader's demand for logic and clarity are at least in some measure satisfied.

The secondary-school graduate cannot be expected to have acquired mastery of highly complex organization in extended discourse, but he should be able to manage the simpler forms. He should know the principles that underlie the writing of a unified paragraph in which he sticks to one main idea to the end, without jumping about from one topic to another; and he should have the ability to construct a theme of from three to five substantial and clearly related paragraphs that follow a single line of thought through to something like adequate development. The author recalls hearing E. L. Miller, formerly assistant superintendent of schools in Detroit, describe the test that he used

${ }^{5}$ Preparation for College English, p. 12. 
for students who wished to be recommended for college. He asked them to write a letter three paragraphs long in which some one topic was developed. If the candidate stuck to his subject, showed a fair command of paragraph and theme structure, and was reasonably literate in this exercise, he got Mr. Miller's approval. A simple test, but one that many college freshmen cannot meet.

Organization is regarded as important in college because it is evidence of whether a student can think straight. The issue is fundamentally one of logic. The student who wrote the sentence, "After 1816, Keats steadily improved as a poet because he had many hardships and difficulties including illness, poverty, and disappointment in love," betrayed at one stroke a quite disorderly, undisciplined mind. His logic was precisely what it would have been had he written, "After 1929, Mr. Jordan steadily prospered, for he had many backsets and tribulations, including illness, the death of his wife, and the loss of his money in the stock crash." The writer has sometimes said that a primary aim of our schools and colleges should be to produce students who could not write such sentences.

Sometimes a lack of logic in organization goes with a fair surface of literacy, even with an appearance of maturity of thought. This is the more insidious for the reason that the teacher, grateful for what is good, may pass by the fundamental error without correction. An example of what I mean is furnished by this opening paragraph which was a part of a college freshman's theme:

It is necessary, however, for schools to realize that feeling is at least on a par with thinking. An educational program in thinking may easily be set up. Lectures, textbooks, discussions, debates, and laboratory experiments all train one's thought processes. But can a program be established for the discipline and control of the emotions? Is it possible to teach students how to feel? Such an education would make us aware of the fact that this world has been governed or misgoverned by emotion, and that progress or retrogression in men's affairs is due to the forces of love, hate, pity, ambition, and good will, as the case may be, among others. The schools plan their training with the assumption that discipline of the mind is more important than any accumulation of facts. In other words, the work in the laboratory and classroom has for its objective a skillful use of our thinking facilities, rather than mere memorization of formulas and techniques.

This starts off well. The writer evidently has a definite problem and is going to attack it head-on. Then, kerplunk! all in a breath he jumps the track completely, and in the last two sentences proposes a quite new issue. It is no wonder that in the paragraphs that followed he got into an inextricable muddle, trying to do justice to his two separate problems. Here is a student who has not yet learned the essential principles of logical organization. His ability to get on in college will depend to a large extent on whether the bad logic shown in this example is evidence of inherent intellectual incapacity or of previous inadequate training. If it is the latter, it is possible that, under more rigorous tutelage, his soul may yet be saved; but if it is the former he is in a bad way. 


\section{Knowledge}

Accompanying the ability to convey ideas with competence and in socially acceptable form, there may be assumed a considerable body of essential knowledge - essential, that is, if the student is to use language with any surety or is to have a basis for continued growth. It will be well if the student knows something about the history and the ways of language, particularly of the English language. And he definitely needs to have a working mastery of fundamental grammatical terms and principles. To be effective, grammar and rhetoric must be functional. But this does not mean that the concepts right expression should go unrecognized, unanalyzed, and unnamed.

Too many students are coming to college these days with virtually no acquaintance with grammar, either functional or descriptive, and with no notion whatever of the rhetorical principles that underlie logical and effective composition. It is not merely that they lack the terms; they lack the concepts for which the terms stand. Try to talk to them about an incoherent, disjointed, and grammar-less theme and you find that you are using a vocabulary which has no meaning for them. Ask them to find for themselves what is wrong with such a theme and you discover that they have no basis for such selfcriticism. On the other hand there are students who have studied much grammar and know all the terms, but only as a system of rules and definitions, with no real understanding of what they mean and with little or no power to apply them. The fortunate student is he whose training represents a more balanced approach, who has both the art and a knowledge of the principles that govern the art.

To be more specific, the writer ventures to offer a list of grammatical and rhetorical terms and principles that the college freshman may be expected to understand. Among grammatical terms would be included Subject, Predicate, Modifier, Phrase, Clause, Direct Object, Predicate (or Subjective) Complement; Noun, Verb, Pronoun, Adjective, Adverb, Conjunction, Interjection, and Substantive; Inflection and Conjugation; Case, Tense, Number, Person, Voice, Gender, Mode, Participle, and Infinite.

Of the rhetorical terms and principles would be named Unity, Coherence, Proportion, Emphasis, Transition, Subordination, Co-ordination, Parallelism, and Inversion; Loose and Periodic; Euphony, Variety, and Balance.

There are in addition, certain negative terms that are essential in discussing faults; such as, Sentence Fragment (Sentence Fault or Incomplete Sentence), Comma Fault (Comma Splice), Dangling Modifier, Faulty Diction, Wordiness (Tautology, Verbosity, Redundancy), "Fine Writing," Faulty Subordination, Bad Phrasing (including Unidiomatic English, Obscure Meaning, etc.), Faulty Reference, Awkward Construction, and Bad Grammar. Mechanics

It goes without saying that the student should know the names and uses of the terms that apply to the mechanics of composition: margin, para- 
graph indentation, syllabication, the marks of punctuation. Punctuation merits especial attention both as a matter of mechanics and as a means to clear and accurate expression. I have șoken in an earlier paragraph of the necessity for aiding students to realize the logic of punctuation. They must see that the right use of commas, semicolons, and colons is a matter neither of rules nor of memory nor of caprice, but rather one of exact thinking, of clear expression, and of regard for the convenience of the reader. Nothing more quickly betrays a slovenly mind than haphazard, illogical punctuation.

Writing of the besetting sins of young students in grammar and mechanics, Mr. Lyons, Headmaster of Rugby, puts bad puctuation at the top of his list of misdemeanors:

These sins are of varying degrees of seriousness, and in some cases betray secrets of deeper disorder. Bad spelling may be carelessness or lack of observation or an eradicable and sometimes inherited disease; but there is nothing inhrently vicious in it. Mistakes of grammar and syntax indicate a misspent youth and a slovenly habit of speech. A clumsy style suggests a lack of aesthetic sensibility and a lumbering mind. But none of these are so depraved as the commoner failing of bad punctuation, which is the sure reflection of inaccurate and slipshod thought. Commas and semicolons are as much a part of the expression of an idea as the words in which it is embodied. They are not (as often seems the case) condiments to be sprinkled freely over the completed paragraph. 6

Mr. Lyons has hardly over-rated the importance of punctuation. One of the specific duties of the English teacher, this author maintains, is to aid the student to rise above these sins. It would be a grand day for the cause of good English in America when a fair proportion of such a job could be done before the student reaches college. A first condition to the attainment of this desirable end would, perhaps, be an abatement of the general scorn that has been these last years so freely heaped on the heads of the "comma-chasers."

\section{READING AND LITERATURE}

Since education is to a considerable extent a widening of mental experience, growth in ability to read is obviously inseparable from a maximum growth of mind. The colleges, therefore, quite properly, covet for their freshmen a high degree of competence in reading. They want, moreover, competence that has been acquired not only in the specialized English course, but in all other subjects as well.

That reading is a basic skill in education has been accepted as a fact so long that reading as a high-school subject is likely to be taken too much for granted. Since children have learned to read in the grades the matter can supposedly be dropped. As a matter of fact learning to read well is a complex and continuous process, and one that is never completed. It used to be assumed, I believe, that when one had learned to read that was the end of it. We now recognize that p. 455 .

"Hugh Lyons, "English in the Science Course," Nature (London), 149 (April, 1942), 
as one passes from subject to subject one must continually learn to read all over again. It is not merely that reading in a new field requires a new vocabulary; it also requires a new set of ideas and apperceptions. And the apperceptive resources will in the end determine the meaning of what one reads. For example, when a boy who is up on his baseball reads that Pitcher Blank won twenty-five games last year he knows at once that Blank had quite a remarkable season on the mound. The concept he gets from this statement is linked with all sorts of comparative information about the records of other pitchers, of Blank's previous record, of what it takes to win so many games, and so on. But the person who has little or no knowledge of baseball would read the same thing, and have no definite concepts at all; he would only read some words and get a meaningless fact.

Now students frequently fail in high school and college (they may be unjustly accused of dullness even) because their chief difficulty is that they haven't gone on learning to read again in each new subject. The teacher may be most to blame here. For it is certainly an important part of the job of every teacher to see to it that his students acquire the power to read in his subject, to work patiently to help them build up the necessary vocabulary and skillfully to help furnish them the requisite appreceptive field for insight into the meaning of the new words and the new statements in terms of their unique significance in context. The English teacher is not and cannot be a teacher of reading in specialized subjects - in botany, in chemistry, in geometry, in shop; that is the job of the instructor in each subject. When every teacher realizes the importance of this fact and cheerfully and intelligently assumes the obligation it imposes, the cause of education will be greatly advanced.

The English teacher, however, has a very special responsibility for teaching reading, one that requires both ability and specific preparation. He has the task of developing the basic skills involved, and he can do much to inculcate habits of careful, thoughtful reading - of looking at words and sentences closely, of sticking to a paragraph until the meaning is clear, of raising questions about what is read, and of debating the validity of statements and conclusions. He is also responsible for training young pupils in the different types of reading: accurate reading for information ("work-type" reading); reading for a general view of a subject; the reading of imaginative literature, both intensively and extensively, for enjoyment and meaning.

Pupils need special help in learning to read imaginative literature, and the one best qualified to give it is the English teacher. There is nothing more worth his time. One of the urgent problems of our age is to find ways to give our youth an education that is both practical and broadly liberal; one that will both prepare a man to take his place in industry, in business, in an office, or on a farm and at the same time lay a foundation for the development of his full potentialities as a human being. We have come to a pass in modern history where we must produce good men or prepare ourselves to see the destruction 
of our civilization, perhaps of the human race. A right liberal education is the most likely solution to this problem. And because good literature is a means to a fuller life - to enlarging men's sympathies, opening their eyes to the feelings and needs of their neighbors, lifting their minds from the subsistence level to a higher plane of ideas, ideals, and realizations - it is one of the most effective instruments of a liberal education, hence one of the best of all agencies for producing good men.

Quite appropriately, then, the colleges expect that, along with general proficiency in reading, their entering freshmen shall have a considerable acquaintance with imaginative literature.

They would like, also, some knowledge of the traditional background materials, such as are found in the Bible and Greek mythology, and of the principal English and American authors and of the periods in which they wrote. But they place first value on the power to read pieces of fiction, poetry, and drama with comprehension and appreciation. They are far less concerned that a student should have read particular works and memorized certain facts than that he should have learned to like good books and have gained from them a better understanding of himself and of the world in which he lives and clearer realizations of the ideas and forces that have molded the destiny of man and have made our modern society what it is.

If, then, one were to set down in brief form some of the principal needs of the high-school graduate in the way of training in reading and literature, the list would run something like this:

I. The ability to comprehend the ordinary prose of newspapers, periodicals, and nontechnical textbooks (as in the social studies).

a. This includes the ability to follow the steps of a straight-forward narrative or argument or explanation and to detect failure in clarity or in logic in such writing.

b. It also includes the ability to put the substance of what has been read into a simple and clear-cut precis or summary in either oral or written form.

2. The ability, gained through practice that has become habitual, to follow a set of directions or instructions.

3. The ability to understand the language of such technical subjects as have been studied in high school and to tackle in an intelligent way the language of new subjects that may be taken up in college, with a fair regard to the apperceptive field such comprehension requires.

4. The ability to read ordinary imaginative literature with enjoyment and with some critical sense of relative aesthetic values.

5. A fair knowledge of some of the principal authors and their works, and of the periods in which they wrote.

6. And in addition to these things some clear perception of the values of reading as a way of knowing better the world in which we live, of understanding ourselves and our fellowmen better, of getting at a broader and deeper conception of the 
social, economic, and political issues that must be solved if our modern world is to be spared the tragedy of going to pot; and, also, along with such understanding, an experience of reading as a satisfaction of curiosity, as an impetus to thought, and as a resource for pleasurable recreation.

\title{
HABITS
}

Knowledge and skills in English have small value until they have eventuated in desirable habits. Good habits come through right practices which have been continued until exceptions are rare. That is why it is of small value to plan an English program with all the written composition work set off in one year, or all the oral work in one term. Good habits in writing and speaking do not come in a day. Some carefully supervised practice in writing and continued exercises in oral English in every term from the grades through senior high school are essential if right habits are to be established. The same may be said of reading. Habits of reading closely for exact meaning, of using the dictionary to look up unfamiliar words, of reflecting sritically on what has been read can be developed only through continuous effort over a considerable period of time. Young people have a remarkable aptitude for sloughing off any acquirement that involves effort and care. It, therefore, becomes an important part of the function of the schools to devise programs and methods that will provide the essential channels to the habitual exercise of skills.

To a considerable extent this whole business of habits in English is a matter of character. For slipshod, slovenly habits in writing and speaking are likely to be but a surface indication of slipshod, slovenly attitudes and thinking and ways of living, of lack of ability or inclination to take pains or to stick to anything until it is well done. Behind all this, such habits indicate a fundamental indifference to excellence, which in turn means an incapacity for excellence for how can one attain excellence who has no ideal of or regard for what is good? The converse is also true: good habits in English indicate positive traits of character. And these are the traits that, consciously or unconsciously, the colleges are looking for in students who come to them from the high schools.

\section{What Language Arts Skills Does a High-School Freshman Need?}

\author{
E D W I N . F U L C OM E R \\ Head of the Department of English, State Teachers College, Montclair, New Jersey
}

NATURE OF THE PROBLEM

\begin{abstract}
1 REv REVIOUS answers to this question have been as numerous as textbook authors and publishers could provide; yet today the problem confronts every high-school principal, every ninth-grade teacher, and every boy and girl who enters high school. The use of an exact prescription which would encompass the language needs of a high-school population of varied abilities, backgrounds, and social opportunities has brought to many students only mis-
\end{abstract}

